\title{
RESPONSE STRATEGIES IN AN INTERNATIONAL STRATEGIC ALLIANCE EXPERIMENTAL CONTEXT: CROSS-COUNTRY DIFFERENCES
}

\author{
Brian V. Tjemkes \\ $V U$ University Amsterdam, the Netherlands \\ Olivier Furrer \\ Radboud University Nijmegen, the Netherlands \\ Koen Adolfs \\ VU University Amsterdam, the Netherlands \\ Arzu Ülgen Aydinlik \\ Istanbul University, Turkey \\ Journal of International Management \\ in Press
}

\section{Correspondence to:}

Olivier Furrer

Radboud University Nijmegen

Nijmegen School of Management

Thomas van Aquinostraat 1

P.O. Box 9108

6500 HK Nijmegen, the Netherlands

Phone: 0031243613079

Fax: 0031243611933

e-mail: o.furrer@fm.ru.nl 


\title{
RESPONSE STRATEGIES IN AN INTERNATIONAL STRATEGIC ALLIANCE EXPERIMENTAL CONTEXT: CROSS-COUNTRY DIFFERENCES
}

\begin{abstract}
International strategic alliances have grown increasingly popular in recent decades, yet their failure rate is extremely high. Poor management of adverse situations contributes significantly to such high failure rates. Moreover, the international environments in which international strategic alliances operate exacerbate the adverse situations and make their management more critical. However, extant research does not specify how people from different national cultures respond to these adverse situations. In order to better understand cross-national differences, this study investigates future managers' preferences for specific response strategies in an international strategic alliance experimental context. Using a scenario-based experiment with 1,379 business students in five countries - Japan, the Netherlands, Switzerland, Turkey, and the United Kingdom - the authors assess whether preferences for seven response strategies - exit, opportunism, aggressive voice, creative voice, considerate voice, patience, and neglect—vary across countries. The results indicate that national culture, both directly and interactively through relationship-level exchange variables that characterize the adversity of the situation, influences response strategy preference. This study advances literature on response strategies by explaining that when faced with the same adverse situation, future managers from different countries likely prefer different response strategies, depending on which response strategies they believe are most adequate in their cultural environment.
\end{abstract}

Keywords: International strategic alliances, national culture, response strategies, exchange 
variables. 


\section{Introduction}

International strategic alliances (ISAs) are voluntary, long-term, contractual, cross-border relationships between two firms, designed to achieve specific objectives through collaboration (Brouthers and Bamossy, 2006). Because of their ability to capitalize on cross-border opportunities, ISAs have grown increasingly popular, yet their failure rate remains high (Park and Ungson, 2001). One of the key drivers of such failures is a lack of sensitivity to cultural differences while managing adverse situations (Jiang et al., 2008; Meschi, 1997). When faced with an adverse situation (e.g., low economic performance, poor relationship quality), managers in an ISA must understand how national culture influences their partners' responses to adversity so they can reduce the likelihood of their alliances' failure. Because ISAs take place within unique socio-cultural contexts, managers also must consider normative beliefs about how people should behave during interactions, which differ across countries (Doney et al., 1998; Thomas and $\mathrm{Au}, 2002)$. Surprisingly then, despite the popularity of ISAs and reports of their high failure rate, we have a limited understanding of how national culture influences people's responses to adverse situations (Aharoni and Brock, 2010; Nakos and Brouthers, 2008).

In an ISA's context, previous studies have examined the influence of national cultural differences between partners on relationship development (Barkema and Vermeulen, 1997; Brouthers and Bamossy, 2006; Meschi, 1997), but they have not systematically identified how people respond to adverse situations nor how culture influences their preference for certain responses. For example, Barkema and Vermeulen (1997) demonstrate that cultural differences between partners increase the likelihood of alliance termination, because differences breed disagreement and conflicts. However, they only focus on alliance dissolution, without examining other possible responses aimed at avoiding dissolution. Brouthers and Bamossy (2006) show that 
within the context of Eastern-Western European joint ventures, cultural differences exacerbate the detrimental effect of adverse situations, but their results indicate that managing adverse situations and cultural differences fosters relationship development and reduces the likelihood of alliance failure. However, their study does not detail the different response strategies that might help manage adverse situations. To better understand how adverse situations can be managed in international strategic alliances, we require more insight into the relationship between national culture and response strategies.

To address this concern, we draw on response strategy literature in which response strategies refer to the unique sets of responses that one party in a relationship uses to deal with adverse situations (Hagedoorn et al., 1999; Ping, 1993; Tjemkes and Furrer, 2010). Extant response strategy literature has focused on the effect of relationship-level exchange variables (i.e., distinct types of adversity), such as partners' satisfaction and exit barriers, on preferences for response strategies (Geyskens and Steenkamp, 2000; Hibbard et al., 2001; Ping, 1993; Tjemkes and Furrer, 2010; Zhou and George, 2001). However, these studies usually implicitly assume that in a given situation, people from any country respond the same way (Boyacigiller and Adler, 1991). Thus, neglecting the issue that national culture is also likely to influence perceptions of the relative importance of exchange variables (Thomas and Au, 2002; Thomas and Pekerti, 2003).

Thus, we develop and test a set of hypotheses that specify direct and interaction effects among national culture (i.e., country), the relationship-level exchange variables that characterize adverse situations, and response strategies. That is, we first propose that national culture directly affects response strategy preference. Second, we examine national culture's moderating effect, through economic and social satisfaction, alliance-specific investments, and alternative availability. The empirical results of a scenario-based experiment with business students (i.e., future managers) from five countries, namely, Japan, the Netherlands, Switzerland, Turkey, and 
the United Kingdom, demonstrate that national culture not only directly influences response strategy preferences but also increases sensitivity to particular types of adverse situations, thus moderating the effect of the situation on preferences for certain response strategies.

We use a scenario-based experimental design and business students to test our hypotheses for several reasons: Given the broad variety of ISAs that exists, both in terms of types and governance forms, an experimental design allows us to control for extraneous factors and confounding effects (Croson et al., 2007; Joardar et al., 2007). In addition, as our hypotheses pertain to fundamental processes concerned with basic and relative stable characteristics of human nature (Bello et al., 2009), which are not specific to ISAs but to more general interpersonal relationships, business students who represent future managers are a pertinent population to study response strategies in a strategic alliance context. Furthermore, the use of a homogeneous sample of business students allows us to improve internal validity (Croson et al., 2007). Moreover, business students are also more likely to only respond to the manipulations than actual managers, whose responses may be contaminated by past experience with a specific existing alliance (Bateman and Zeithaml 1989). The use of an experimental design with business students, however, might raise the issue of external validity. To alleviate this issue, we test two important assumptions of our experimental design by conducting a survey of actual alliance managers. This survey allows us to assess the validity of our measures of response strategies and the direct effects relationship-level exchange variables that are manipulated in the experiment. The results show that the response strategy measures are valid and that the effects of the exchange variables are as expected.

Accordingly we advance response strategy literature by demonstrating that national culture influences people' perceptions of the adversity of the situation, with an accordant interactive effect on their response strategy preferences. By shifting the focus of our research from assessing 
the overall effect of cultural differences on the adverse situation to the underlying direct and moderating mechanisms by which national culture influences response preferences, our study demonstrates that when faced with the same adverse situation, respondents from different countries are likely to prefer different response strategies, depending on which strategies they believe are most adequate in their cultural environment. Even if our results are obtained from business students in an experimental context, they concern fundamental processes that are likely to be present in actual ISAs. Therefore, the recognition of these cultural effects is useful to help international strategic alliance managers, because with a better understanding of the behavioral intentions of their foreign partners, as well as their own preferences, they can better overcome adverse situations.

We organize the remainder of this article as follows: In the next section, we define and classify response strategies. Then we introduce cultural dimensions to develop hypotheses about their direct and moderating effects on preferences for response strategies. In the method section, we describe the sample and the design of the scenario experiment we use to test the hypotheses. Finally, we present the results and conclude with a discussion of the theoretical and managerial implications of our study, along with limitations and directions for further research.

\section{Theoretical Background}

\subsection{Response strategies}

Hirschman's (1970) exit, voice, and loyalty framework provides the foundation for an important stream of research on response strategies. Hirschman initially represented exit, voice, and loyalty as three alternative strategies along a constructive-destructive spectrum (Leck and Saunders, 1992). Extending Hirschman's framework with a fourth strategy, Farrell (1983) and Rusbult and Zembrodt (1983) propose the ELVN (exit-voice-loyalty-neglect) typology, which 
represents a parsimonious conceptualization of response strategies and derives its strength from the underlying two-dimensional structure into which the four response strategies are organized: an active-passive and a constructive-destructive dimension. In later studies, three types of voice have been distinguished: considerate, creative, and aggressive voice (Hagedoorn et al., 1999; Zhou and George, 2001). Opportunism also joins the typology as an active-destructive strategy (Ping, 1993). Thus, seven response strategies appear in previous literature: exit, opportunism, aggressive voice, creative voice, considerate voice, patience, and neglect (Tjemkes and Furrer, 2010).

Exit indicates a disinclination to continue the current relationship (Hirschman, 1970), which is the ultimate and most destructive response to an adverse situation. It can be either active or passive (Hagedoorn et al., 1999). By exiting the alliance, partners dissolve their relationship and must find alternative ways to achieve their objectives (Rusbult et al., 1982; Withey and Cooper, 1989). Opportunism represents an active-destructive response (Wathne and Heide, 2000), because it is an active attempt to increase benefits from the alliance in ways that are explicitly or implicitly prohibited (Ping, 1993). Three types of voice represent three additional strategies: aggressive, creative, and considerate (Hagedoorn et al., 1999; Tjemkes and Furrer, 2010; Zhou and George, 2001). Considerate voice is constructive and slightly active and represents an attempt to change, rather than escape from, the adverse situation by communicating in a relationship-preserving manner and cooperatively discussing problems (Hagedoorn et al., 1999; Ping, 1993). Aggressive voice is more destructive and more active; it refers to the forceful imposition of views on alliance partners, without trying to avoid conflicts (Hagedoorn et al., 1999; Hibbard et al., 2001). The third type of voice, creative voice, pertains to the generation of novel and potentially useful solutions to address the situation, which makes it both active and constructive (Zhou and George, 2001). With patience, a partner silently abides the issues, with 
the confidence that things will improve in the future (Hibbard et al., 2001; Ping, 1993). It requires voluntarily ignoring the issue, in the hope that the adverse situation resolves itself, and the belief that undesirable circumstances are transitory phenomena that dissipate over time (Ping, 1993). It thus is constructive and passive. Finally, neglect is passive but destructive, because it allows a relationship to deteriorate (Rusbult et al., 1982). A neglectful manager believes that the alliance does not deserve to be salvaged and expends little effort to keep it afloat (Ping, 1993; Pressey and Qu, 2007).

\subsection{Adverse situations and exchange variables}

Building on social exchange theory (Blau, 1964) and interdependence theory (Thibaut and Kelley, 1959), Rusbult and colleagues (Rusbult and Farrell, 1983; Rusbult et al., 1988) propose that preferences for active-passive and constructive-destructive response strategies depend on relationship-level exchange variables that characterize the nature of the adverse situation. Over time, their investment model has been tested empirically in several contexts, including job satisfaction (Rusbult and Farrell, 1983; Rusbult et al., 1988), romantic relationships (Rusbult and Zembrodt, 1983), channel relationships (Geyskens and Steenkamp, 2000; Ping, 1993), and strategic alliances (Tjemkes and Furrer, 2010). Among these studies those focusing on alliances identified four exchange variables that influence preferences for response strategies: economic satisfaction, social satisfaction, alternative attractiveness, and alliance-specific investments. These exchange variables represent different adverse situations in ISAs to which managers must respond.

Economic satisfaction pertains to managers' evaluation of the financial outcomes of an alliance (Geyskens and Steenkamp, 2000). According to Geyskens and Steenkamp (2000), an economically satisfied manager considers the alliance a success with respect to goal attainment, 
effectiveness, productivity, and the resulting financial outcomes. Prior response strategy research has produced results indicating that economic satisfaction influences managers' response preference on the active-passive dimension but not on the constructive-destructive one. Low economic satisfaction implies that managers perceive a discrepancy between prior expectations and desired financial results (Geyskens and Steenkamp, 2000), which requires an active response to improve the situation rapidly (Das, 2006; Tjemkes and Furrer, 2010). However, this active response could be destructive, such as acting opportunistically to extract additional financial benefits, or constructive, such as using creative voice to find new ways to solve the situation. Regardless of how they do it, managers are more likely to "rock the boat" to restore performance and increase their economic satisfaction, instead of waiting patiently for the situation to improve (Ping, 1993). In contrast, managers who are satisfied with the economic performance of the alliance likely behave passively (Geyskens and Steenkamp, 2000; Tjemkes and Furrer, 2010); they can either be patient or neglect the issue.

Social satisfaction pertains to managers' evaluations of the psycho-social aspects of an alliance; it implies that interactions with counterparts are fulfilling, gratifying, and facile (Geyskens and Steenkamp, 2000). Managers' perceptions of relational quality affect their social satisfaction; if relational quality is poor, the alliance suffers dysfunctional conflicts, distrust, and low commitment (Ariño et al., 2001). Empirical results suggest that social satisfaction in turn influences the constructive-destructive dimension but not the active-passive one. Low social satisfaction creates greater suspicion about a counterpart's intentions and reduces expectations about the potential future benefits of the relationship (Geyskens and Steenkamp, 2000). Therefore, managers dissatisfied with relationship quality may terminate the relationship rather than try to save it through constructive responses (Tjemkes and Furrer, 2010). To do so, they can respond destructively, either in an active way by acting opportunistically or in a passive way by 
exiting the relationship or being neglectful. Partners satisfied with the relationship instead appreciate the contacts with their counterparts, and the relationship likely is characterized by trust, respect, and commitment (Ariño et al., 2001). In such a situation, managers should use constructive response strategies (Brouthers and Bamossy, 2006), whether active or passive. For example, Hibbard and colleagues (2001) argue that managers with positive views of a relationship place less importance on an adverse situation and instead remain patient, believing that the transient negative situation will improve. Geyskens and Steenkamp (2000) confirm that socially satisfied managers are more likely to use creative or considerate voice.

Alliance-specific investments represent sunk costs that cannot be redeployed easily to another alliance without some sacrifice in the productivity of the assets or cost to adapt them (Ping, 1993). These investments would be lost if the alliance were dissolved, so they act as exit barriers. Their presence constitutes a source of dependence for the firm that makes them, which implies an adverse situation for managers who need to reduce the negative consequences of their firms' vulnerable position. The presence of unilateral, alliance-specific investments triggers constructive response strategies and inhibits destructive ones (Hirschman, 1970; Tjemkes and Furrer, 2010), because constructive responses reduce the risk of losing the investments if the relationship terminates prematurely. In the case of high alliance-specific investments, constructive responses may either be active, such as using creative or considerate voices to demonstrate commitment to the relationship, or passive, such as being patient to reduce the negative effect of the dependence. When alliance-specific investments are low though, managers have more latitude to act destructively, because their lesser dependence on their partner means they may exit the relationship, become more neglectful, or act opportunistically without fear of retaliation. The results of previous response strategy research support this logic (e.g., Ping, 1993).

Finally, alternative availability refers to the extent to which the firm possesses attractive 
alternatives outside the alliance that could enable it to attain its objectives (Ping, 1993). The presence of attractive alternatives provides firms with a source of power, whereas a dearth of alternatives increases dependence on counterparts. In an adverse situation without alternatives, managers have strong incentives to make the current alliance work and likely respond actively to improve the situation (Buchanan, 1992). For example, they might constructively use considerate and creative voice to ensure their partner collaboration, but because they do not depend on their partner, they also can use aggressive voice or opportunism if their partner is not cooperative. Moreover, if managers perceive that they have other alternatives for achieving their objectives, they depend less on the current relationship, which increases the likelihood of exit and passive strategies such as neglect and patience (Ping, 1993; Tjemkes and Furrer, 2010).

Although in general empirical studies support the directions of the effects of the exchange variables on response strategy preference, the strength of the relationship varies across studies. By focusing solely on the effect of exchange variables, prior literature grounded in the investment model implicitly has assumed that with a specific combination of exchanges variables, every manager will prefer the same response strategies. For example, Tjemkes and Furrer (2010) in an experimental study in the Netherlands find that economic satisfaction, social satisfaction, alliance-specific investments, and the availability of attractive alternatives differentially and interactively affect response strategies. However, in their study, they neglect contextual variables, such as national culture, and their influence. In an international context, national culture likely influences managers' preference for a response strategy (e.g., Lee and Jablin, 1992; Morris et al., 1998; Radford et al., 1993), as well as their perception of the adversity of the situation; thus, it should moderate the effect of exchange variables (Thomas and Au, 2002; Thomas et al., 2003). We therefore develop hypotheses related to both the direct and moderating effects of national culture on response strategy preference. 


\section{Hypothesis development}

To understand international differences in response strategy preference, we turn to Hofstede (2001), who identifies four cultural dimensions: individualism-collectivism, masculinityfemininity, power distance, and uncertainty avoidance. We focus on these cultural dimensions to explain country differences (Taras, Rowney, and Steel, 2009) because they enable us to disentangle theoretically the direct and interaction effects of a country on response strategy preference (per Thomas and Pekerti, 2003). National culture and the country are not the same, yet country offers a good proxy for national culture (Hofstede, 2001). We hypothesize specifically that the individualism-collectivism and uncertainty avoidance cultural dimensions influence the active-passive (not constructive-destructive) dimension of response strategy preference and that the power distance and masculinity-femininity cultural dimensions influence the constructivedestructive (not active-passive) dimension. In addition, we predict that the individualismcollectivism and uncertainty avoidance cultural dimensions interact with two exchange variables, economic satisfaction and alternative availability, in affecting the same active-passive dimension of response strategies. Similarly, we hypothesize that the power distance and masculinityfemininity cultural dimensions interact with social satisfaction and alliance-specific investments, because they affect the same constructive-destructive dimension of response strategies.

Our hypotheses about the direct and moderating effects of national culture on response strategy preferences concern fundamental cultural processes, which pertain to interpersonal relationships. However, as we test them in an experimental ISA context, we frame them in such a context. Moreover, as we use business students acting as alliance managers rather than actual alliance managers to test these hypotheses, we refer to future managers when we present the specific relationships we test. 


\subsection{Individualism-collectivism}

The individualism-collectivism dimension refers to societal norms regarding individualgroup obligations and relationships. That is, individualism describes cultures in which the ties between individuals are loose (Hofstede, 2001). Thus within an alliance context, responsibility for action and responses to adverse situations lies within individual managers, who are more likely to be active, using different forms of voice or acting opportunistically. In collectivist cultures, the group is the dominant structure, and most actions reflect a consideration of their effect on the group and its members (Hofstede, 2001), so responsibility for action and response lies within the group. In collectivist cultures, decision-making processes and responses to adversity are guided by consensus (Thomas et al., 2003), which results in more passive responses (Yum, 2004). In such cultures, future managers likely prefer, more than those in individualistic countries, to exit the relationship or be neglectful or patient (Pressey and Qu, 2007).

In countries with an individualistic culture, decision-making processes and responses to adverse situations reflect motives pertaining to the protection of individual profits, as justified by utilitarian principles (Thomas et al., 2003). Thus, if the relationship is perceived as valuable, future managers in individualist countries will prefer constructive strategies. However, when the relationship loses its value, they will act destructively. Compared with individualistic countries, people in countries with a collectivist culture are inclined to consider their business exchange partners as out-groups (Nakana, 1971), especially if they are foreigners (Johnson et al., 1996). Therefore, in an adverse situation, they will not hesitate to use destructive strategies to protect group harmony and save face. However, when responding constructively is in the best interest of the group, they will do so to maintain the status quo and limit actions that might disrupt in-group harmony (Triandis, 1995). Thus, in an alliance context, future managers in both individualistic and collectivistic countries should prefer constructive and destructive responses in similar ways. 
However, because the individualism-collectivism dimension affects active-passive and not constructive-destructive response preferences, we hypothesize that within the context of alliances in individualist countries, active response strategies are relatively more preferred than passive response strategies, compared with collectivistic countries.

Hypothesis 1a: In individualist countries, active response strategies (opportunism, aggressive, creative, and considerate voices) are preferred relatively more and passive strategies (patience, neglect, and exit) relatively less than in collectivistic countries.

Also in relation to individualism-collectivism, economic satisfaction influences the degree of activeness and passiveness in response preference, such that these factors likely interact. Achieving economic satisfaction is a more important goal in individualistic countries than in collectivist countries, because alliances in the former are governed by more rational cost-benefit calculations (Triandis, 1995). Therefore, when economic satisfaction decreases, future managers in individualistic countries are more likely than their counterparts in collectivist countries to prefer active response strategies and less likely to prefer passive strategies to solve the situation (Thomas and $\mathrm{Au}, 2002$ ). In contrast, future managers in collectivist countries are less sensitive to changes in economic satisfaction, as the quality of the relationship with their partner is more important than its short-term financial outcomes. Therefore:

Hypothesis 1b: In individualistic countries, the negative effect of economic satisfaction on active response strategies and the positive effect of economic satisfaction on passive strategies are weaker than they are in collectivistic countries.

Similar to the effect of economic satisfaction, the presence of attractive alternatives should influence the degree of activeness and passiveness of future managers' response strategy preference, so we expect alternative attractiveness to interact with the individualism-collectivism cultural dimension. In individualistic countries, which better tolerate self-serving behaviors and 
relationships based on cost-benefit calculations (Triandis, 1995), future managers without attractive alternatives feel threatened by the risk that their counterpart will prefer to exit the alliance; to reduce their dependence (Thomas and $\mathrm{Au}, 2002$ ), they prefer active strategies more and passive strategies less than managers in collectivistic countries. Future managers from countries with collectivist cultures instead are used to depending on their group and therefore might feel less threatened by a dependence situation created by a lack of alternatives. Therefore, they are likely to be less influenced by the existence or absence of alternatives, because they do not consider the situation especially adverse. Thus, we hypothesize:

Hypothesis 1c: In individualistic countries, the negative effect of alternative availability on active response strategies and the positive effect of alternative availability on passive strategies are stronger than they are in collectivistic countries.

\subsection{Masculinity-femininity}

The masculinity-femininity cultural dimension pertains to norms regarding an achievement motivation versus quality of life. Masculine cultures convey norms that emphasize the need for autonomous, competitive, and assertive actions to achieve materialistic goals (Hofstede, 2001; Hofstede and Usunier, 2003). In contrast, in countries with a feminine culture, the dominant norms emphasize collaboration, relationships, and caring for others (Hofstede, 2001; Hofstede and Usunier, 2003). Masculine cultural norms favor ego-boosting behaviors and sympathy for the strong, which suggests a preference for destructive, less constructive behaviors. In such countries, conflicts get resolved through fighting, in an effort to "get things straight." Thus, in an alliance context, future managers from masculine countries likely prefer more destructive response strategies compared with future managers from feminine countries. In contrast, feminine cultural norms exhibit a pattern of nurturance, which emphasizes less destructive and more constructive 
behavior (Doney et al., 1998). Feminine cultural norms also emphasize modesty (Hofstede, 2001), as reflected in a preference for compromises and less destructive response strategies, such as creative and considerate voices and patience (Doney et al., 1998; Hofstede and Usunier, 2003).

However, the masculine-feminine cultural dimension does not influence the degree of activeness-passiveness of future managers' response strategy preference. In masculine countries, destructive strategies are preferred over constructive ones, independent of their degree of activeness or passiveness. These countries value competition and assertive actions (Hofstede, 2001; Hofstede and Usunier, 2003), so future managers are more likely to use aggressive voice, act opportunistically, exit the relationship, or act neglectfully than use constructive strategies, compared with those in feminine countries. In contrast, in feminine countries, in which the dominant norms emphasize collaboration and relationships (Hofstede, 2001; Hofstede and Usunier, 2003), future managers use constructive strategies, such as creative and considerate voices and patience, independent of the degree of activeness-passiveness, more so than destructive strategies, in comparison with those in masculine countries. Thus, we propose that the masculine-feminine cultural dimension affects the constructiveness-destructiveness of future managers' response strategy preferences, not the activeness-passiveness of this preference.

Hypothesis 2a: In masculine countries, destructive response strategies (neglect, exit, opportunism, and aggressive voice) are preferred relatively more and constructive strategies (creative and considerate voices, and patience) relatively less than in feminine countries. Because social satisfaction and the masculinity-femininity cultural dimension both influence the degree of constructiveness versus destructiveness, we posit that they interact. In masculine countries, social harmony and cooperative relationships are not goals in themselves, and fighting is a means to clarify a situation. Thus, future managers likely prefer destructive strategies over constructive strategies, compared with future managers in feminine cultures, irrespective of their 
level of social satisfaction. In contrast, social harmony and good relationship quality are critically important in feminine countries, which tolerate socially dissatisfying relationships far less than do masculine cultures (Hofstede and Usunier, 2003). Therefore in feminine countries, social satisfaction should have a stronger effect on response strategy preference than it does in masculine cultures. As social satisfaction increases, future managers from feminine countries, who value consensus and close relationships (Hofstede, 2001), respond more constructively, whereas when social satisfaction decreases, they likely respond more destructively. Thus: Hypothesis 2b: In masculine countries, the positive effect of social satisfaction on constructive response strategies and the negative effect of social satisfaction on destructive strategies are weaker than they are in feminine countries.

Similar to the effect of social satisfaction, the presence of alliance-specific investments should influence the degree of constructiveness-destructiveness of future managers' response strategy preference, so we expect alliance-specific investments to interact with the masculinityfemininity cultural dimension. As mentioned, feminine countries value close relationships (Hofstede, 2001), so future managers who have made alliance-specific investments do not perceive their dependence on their partner as a threat and are more likely than those from masculine countries to prefer constructive responses that protect the quality of their relationship, even if such behavior could increase their dependence. Therefore in feminine countries, future managers are more likely to prefer constructive responses and less likely to prefer destructive responses than in masculine cultures, irrespective of the amount of their alliance-specific investments. In contrast, when future managers from masculine countries perceive alliancespecific investments as high, they likely feel threatened by their dependence on their counterpart, and to escape this dependence, they tend to prefer destructive response strategies, not constructive responses, relative to situations with low alliance-specific investments. Thus, we 
hypothesize:

Hypothesis 2c: In masculine countries, the positive effect of alliance-specific investments on constructive response strategies and the negative effect of alliance-specific investments on destructive strategies are weaker than they are in feminine countries.

\subsection{Power distance}

Power distance pertains to norms for the acceptable distribution of power in a society, that is, the degree to which less powerful members within a society expect and accept that power is distributed unequally (Hofstede, 2001). Inequality in small power distance countries is a necessary evil that should be minimized; in large power distance countries, inequality is the basis of societal order (Hofstede, 2001). Therefore, in large power distance countries, the use of power through destructive strategies, such as exiting the relationship, opportunism, aggressive voice, or neglect, demands less legitimization than it would in small power distance countries. In small power distance countries though, the dominant cultural norm of harmony between the powerful and powerless favors constructive response strategies, such as creative and considerate voices and patience, because they are more likely to preserve the relationship between alliance partners.

Because power distance relates to the distribution of power within a society, which can take both active and passive (i.e., potential power) forms, the power distance cultural dimension is not likely to influence the activeness or passiveness of future managers' response strategy preference. Specifically, in large power distance countries, future managers may prefer both active and passive destructive response strategies over constructive ones, often by legitimizing neglect and aggressive voice. In small power distance countries, patience and considerate and constructive voices are all constructive strategies, whether active or passive, that can protect harmony. Thus, the power distance cultural dimension likely affects the constructiveness-destructiveness of 
response strategy preference but not the active-passive dimension:

Hypothesis 3a: In high power distance countries, destructive response strategies (neglect, exit, opportunism, and aggressive voice) are preferred relatively more and constructive strategies (creative and considerate voices, and patience) relatively less than in low power distance countries.

Because both social satisfaction and the power distance cultural dimension influence the degree of constructiveness versus destructiveness of the response strategy preference, we posit that they interact. As in masculine countries, in large power distance countries, social harmony and cooperative relationships are not goals in themselves. Future managers in such countries therefore are more likely to prefer destructive strategies and less likely to prefer constructive strategies compared with future managers in small power distance countries, regardless of their level of social satisfaction. In contrast, social harmony and good relationship quality are critically important in small power distance countries, which tolerate socially dissatisfying relationships far less than do large power distance countries (Hofstede, 2001). Therefore in small power distance countries, social satisfaction should have a stronger effect on response strategy preference than in large power distance cultures. As social satisfaction increases, future managers from small power distance countries likely respond more constructively, whereas when social satisfaction decreases, they are likely to respond more destructively. Thus:

Hypothesis 3b: In high power distance countries, the positive effect of social satisfaction on constructive response strategies and the negative effect of social satisfaction on destructive strategies are weaker than in low power distance countries.

Similar to the effect of social satisfaction, the presence of alliance-specific investments can influence the degree of constructiveness and destructiveness of future managers' response strategy preference, so we expect alliance-specific investments to interact with the power distance 
cultural dimension. Power distance deals with the need for dependence versus interdependence in society (Hofstede, 2001). In high power distance countries, people strive for independence; in small power distance countries, they likely accept interdependence with partners. Therefore, when the amount of alliance-specific investments increases, future managers in large power distance countries are likely to react more constructively and less destructively to reduce the risks related to their dependence. On the contrary, in countries with small power distance, when the amount of alliance-specific investments increases, future managers do not feel more threatened, nor do they respond differently than they would in situations with low levels of alliance-specific investments.

Hypothesis 3c: In high power distance countries, the positive effect of alliance-specific investments on constructive response strategies and the negative effect of alliance-specific investments on destructive strategies are weaker than in low power distance countries.

\subsection{Uncertainty avoidance}

Uncertainty avoidance pertains to the degree to which the members of a society feel uncomfortable with uncertainty and ambiguity (Hofstede, 2001). In an alliance context, future managers in high uncertainty countries seek to reduce uncertainty by engaging in passive response strategies, rather than active ones, to reduce the risk of harmful partner retaliatory behavior. Passive response strategies, such as patience and neglect, or even exit, are perceived as less uncertain than more active ones, such as different types of voice and opportunism. In contrast, we expect that future managers from higher uncertainty countries prefer more active response strategies, which may result in more uncertain outcomes. In countries with low uncertainty avoidance, people are more willing to accept uncertainty and not afraid to take risks. 
Uncertainty avoidance is less likely to influence the degree of constructivenessdestructiveness of future managers' response strategy preference, because active strategies seem more uncertain, irrespective of their constructiveness or destructiveness. For example, opportunism may trigger retaliatory behavior, but creative voice is also ambiguous, because it challenges the status quo. In contrast, constructive and destructive passive strategies appear less risky, because they allow for more time and their effects emerge only in the longer term. Therefore, the degree of constructiveness-destructiveness is not likely to be influenced by the uncertainty avoidance cultural dimension. We postulate that uncertainty avoidance instead affects the activeness-passiveness of future managers' response strategy preferences.

Hypothesis 4a: In countries with high uncertainty avoidance, active response strategies (opportunism, aggressive, creative, and considerate voices) are preferred relatively less and passive strategies (patience, neglect, and exit) relatively more than in countries with low uncertainty avoidance.

Economic satisfaction also influences the degree of activeness and passiveness in response preference, so these two factors should interact. Achieving short-term economic performance is a more important goal in high uncertainty avoidance countries than in low uncertainty avoidance countries. Therefore, when economic satisfaction is low, future managers in high uncertainty avoidance cultures are more likely than those in low uncertainty avoidance countries to prefer active and less likely to prefer passive response strategies to reduce the ambiguity created by low economic performance. In contrast, future managers in low uncertainty avoidance countries are less sensitive to changes in economic satisfaction, because they are less afraid of uncertainties and ambiguities, such that they may trade off short-term performance losses for long-term benefits.

Hypothesis 4b: In high uncertainty avoidance countries, the negative effect of economic 
satisfaction on active response strategies and the positive effect of economic satisfaction on passive strategies are stronger than in low uncertainty avoidance countries.

Finally, and similar to the effect of economic satisfaction, the presence of attractive alternatives should influence the degree of activeness and passiveness of future managers' response strategy preference and interact with the uncertainty avoidance cultural dimension. In high uncertainty avoidance countries, future managers without attractive alternatives feel threatened that their counterpart will prefer to exit the alliance, so to reduce the ambiguity and uncertainty related to their dependence, they prefer active strategies more and passive strategies less, compared with future managers from low uncertainty avoidance countries. In contrast, those from low uncertainty countries are less threatened by the uncertainties of a dependence situation created by a lack of alternatives. They are then less influenced by the availability of attractive alternatives, and we hypothesize:

Hypothesis 4c: In high uncertainty avoidance countries, the negative effect of alternative availability on active response strategies and the positive effect of alternative availability on passive strategies are stronger than in low uncertainty avoidance countries.

\section{Methodology}

To test the hypotheses empirically, we designed a scenario-based experiment, a method that has proven useful for studying response strategies (Lee and Jablin, 1992; Rusbult et al., 1988; Tjemkes and Furrer, 2010) and international management decisions (Joardar et al., 2007). Furthermore, with an experiment, we can examine causal relationships between predictors and outcomes in controlled conditions (i.e., reduce impact of confounding effects), which makes this method particularly suitable for disentangling direct and moderating effects (Bateman and Zeithaml 1989; Croson et al., 2007). 


\subsection{Sample}

To assess the effects of national culture differences on response strategies, we collected data in five countries: Japan, the Netherlands, Switzerland (French-speaking part), Turkey, and the United Kingdom. These five countries systematically vary according to the four cultural dimensions of Hofstede, ranging from 37 to 89 for individualism, from 14 to 95 form masculinity, from 35 to 70 for power distance and from 35 to 92 for uncertainty avoidance (see Table 1). We focus on Hofstede's dimensions rather than others, given evidence that it has had far greater impact (Kirkman et al, 2006). In addition, even if Hofstede's scores have been criticized for being outdated and collected in a specific context, recent meta-analysis (Taras et al., in press) and data (Ralston et al., in press) show that if country scores tend to converge over time, the relative position of our five countries is relatively stable.

[Insert Table 1 about here]

We collected 1,379 questionnaires from business students enrolled in masters' programs (M.Sc.) in Japan, the Netherlands, Switzerland, Turkey, and the United Kingdom. Only students born and raised in their country were retained in the final samples. The Dutch sample consisted of 334 students, with an average age of 24.4 years, $35.5 \%$ of whom were women. The Swiss sample consisted of 255 business students with an average age of 23.3 years, $42.4 \%$ of whom were women. The Turkish sample consisted of 278 students, with an average age of 23.3 years, $49.6 \%$ of whom were women. The Japanese sample consisted of 262 respondents with an average age of 24.4 years, $32.1 \%$ of whom were women. The U.K. sample consisted of 250 students with an average age of 23.7 years, and $46 \%$ of them were woman.

As our hypotheses are not specific to ISAs but to more general interpersonal relationships and pertain to relative stable characteristics of human nature (Bello et al., 2009), two arguments support our decision to use business students, as respondents. First, the use of a homogeneous 
sample of business students allows us to improve internal validity (Croson et al., 2007). Second, compared to actual managers, whose responses may be contaminated by past experience with a specific existing alliance (framing bias), business students are more likely to only respond to the manipulations (Bateman and Zeithaml 1989). In addition, as they represent future managers, they are likely to understand the strategic alliance context of the experiment.

As already mentioned the use of business students may raise the issue of external validity, therefore to assess the validity of our results, we collected additional survey data from a sample of 135 Dutch alliance managers (average age $=42.6$ years $[\mathrm{SD}=9.0]$; average alliance management experience $=4.1[\mathrm{SD}=1.8]$ on seven-point experience scale; $69.6 \% \mathrm{men})$, and compared their results with those of the Dutch business students. This comparison allows us to test the validity of our measurement and manipulations.

The questionnaire, originally developed in English, was translated into Japanese and Turkish, following standard translation and back-translation procedures. Students in the Netherlands, Switzerland, and the United Kingdom used the English version of the questionnaire, because English was the language used in their study programs.

\subsection{Scenario-based experiment}

To capture adverse situations, we manipulated economic satisfaction, social satisfaction, alliance-specific investments, and the availability of alternatives (per Tjemkes and Furrer, 2010). The experiment in each country used a four-factor (exchange variables) by two level (positive versus negative) between-subjects design, in which we combined the manipulations to form 16 different scenarios, though we removed the all-positive (i.e., not adverse) scenario. Each experiment was conducted over multiple sessions, in which we assigned each participant randomly to one of the 15 scenarios. The participants assumed the roles of alliance managers and 
indicated how they would respond to the adverse situation presented in the scenario. The text of the scenarios appears in the Appendix.

To manipulate economic satisfaction, we varied the financial outcomes of the alliance, such that it produced either beyond or below their expectations. The social satisfaction manipulation centered on relationship quality. The quality of the relationship referred to the extent to which the firms developed a relationship characterized by trust, commitment, and adaptability, which eliminated the need for substantial monitoring costs. For the alliance-specific investment manipulation, we varied the extent to which the focal firm made substantial investments in the alliance and could expect switching costs. Specifically, the focal firm either invested little or substantially and could or could not expect additional costs from penalty fees if the alliance ended prematurely. Finally, we manipulated the availability of alternatives as the extent to which the focal firm had other means to realize its objectives, whether many or only a few available alliance partners.

\subsection{Response strategy measures}

To operationalize the seven response strategies, we turned to existing scales and, when necessary, adapted them to the context of ISA. We measured exit with items pertaining to whether the respondent intended to end the relationship or stop doing business with the partner (Rusbult et al., 1982; Withey and Cooper, 1989). The measures for opportunism, adapted from Ping (1993) and Wathne and Heide (2000), included withholding information, exaggerating the adverse nature of the situation, and escaping from contractual obligations. Aggressive voice items referred to pushing a solution forcefully or being persistent (Hibbard et al., 2001). For creative voice, we used items related to the creation of innovative and creative solutions or fresh ideas (Zhou and George, 2001). To measure considerate voice, the items indicated working to create a 
consensus and finding a solution satisfactory and acceptable for everyone (Ping, 1993). We operationalized patience with items such as optimistically waiting for better times and trusting that the situation would resolve itself (Hibbard et al., 2001; Ping, 1993). For neglect, the items referred to not dealing with the issue, not putting additional effort into the relationship, and not presenting initiatives to improve the situation (Ping, 1993). All these measures used seven-point Likert scales, ranging from "I would definitely not react in this way" [1] to "I would definitely react in this way" [7]. The list of items appears in Table 2.

[Insert Table 2 about here]

\subsection{Control variables}

To take into account the potential effect of noncultural factors, we also measured several control variables: A single-item scale assessed perceptions of the severity of the situation, which can influence the choice of response strategies (Rusbult et al., 1988). In addition, because some response strategies may be more socially desirable (considerate voice) than others (opportunism), we included the M-C2 version of the Marlowe-Crowne Social Desirability scale (Strahan and Gerbasi, 1972). Finally, we measured the respondents' age and gender, because these personal characteristics may influence preferences for response strategies (e.g., Rusbult et al., 1988).

\section{Analyses and results}

We conducted four sets of analyses to examine the data. First, we assessed the reliability and construct validity of the response strategy measures using Cronbach's alpha and the composite reliability (CR) coefficients, as well as the factor loadings from confirmatory factor analyses (CFAs) conducted in each country separately. Second, we ran a series of multigroup CFAs to assess the degree to which the seven-factor model is invariant across the four countries. Third, to examine the direct and moderating effects of country differences and test the hypotheses, we 
conducted a multivariate analysis of covariance (MANCOVA), followed by a series of post-hoc country comparisons and $F$-tests. Because the response strategies were interrelated, we manipulated the scenario variables, and we used covariates to control for confounding effects, a MANCOVA was the most appropriate method (Huberty and Morris, 1989). Fourth, to examine the external validity of the findings, we collected additional data from alliance managers in the Netherlands and assessed the measurement equivalence and similarity of their responses with those from the business students in our Dutch sample.

\subsection{Construct validity and cross-cultural invariance of the response strategies}

We conducted a separate CFA for each country to test the proposed seven-factor response strategy structure. The alphas and CR greater than or equal to .70, along with factor loadings that exceed .50, suggest acceptable reliability and convergent validity (Nunnally and Bernstein, 1994). We tested seven-factor models rather than the seven dimensions separately so that we could investigate the discriminant validity of the seven response strategies simultaneously (Perrinjaquet et al., 2007). We employed maximum likelihood estimation procedures, because the data do not strongly violate multivariate normality assumptions (McDonald and Ho, 2002). Following common practice (e.g., Byrne, 2001; Hu and Bentler, 1999), we also used multiple indicators to assess model fit, namely, the normed chi-square $\left(\chi^{2} /\right.$ d.f. $)$, root mean square error of approximation (RMSEA), standardized root mean square residual (SRMR), non-normed fit index (NNFI), and comparative fit index $(\mathrm{CFI})$, and we required $\mathrm{RMSEA} \leq .06, \mathrm{SRMR} \leq .08, \mathrm{NNFI} \geq$ .90 , and CFI $\geq .95$, as well as $\chi^{2} /$ d.f. less than or equal to 2 , to confirm good model fit.

We used AMOS 17.0 to estimate a seven-factor CFA model with the 21 response strategy items for each country. The analyses reveal no offending estimates in any of the models. The country models possess good fit (see Table 3); the normed chi-square values are 1.53, 1.50, 1.54, 
1.98, and 1.57, for Japan, the Netherlands, Switzerland, Turkey, and the United Kingdom respectively. In addition, other goodness-of-fit indices suggest acceptable fit: The RMSEA values range from .031 [90\% confidence interval (CI): .013, .044] for the United Kingdom to $.059[90 \%$ CI: .050, .069] for Turkey, below the cut-off value. The other indices also suggest a good fit; for Japan, the fit indices are .058 (SRMR), .95 (NNFI), and .96 (CFI); for the Netherlands, these values are .049 (SRMR), .96 (NNFI), and .97 (CFI); for Switzerland, they are .052 (SRMR), .95 (NNFI), and .96 (CFI); for Turkey, .059 (SRMR), .90 (NNFI), and .92 (CFI); and for the United Kingdom, they are .046 (SRMR), .95 (NNFI), and .96 (CFI). The Turkish CFI is thus slightly below the expected value but sufficient.

[Insert Table 3 about here]

To assess convergent validity, we examined the factor loadings, which are significant and exceed the .50 threshold, ranging from .53 to .85 in the Japanese sample, .56 to .90 in the Dutch sample, .51 to .89 in the Swiss sample, .55 to .88 in the Turkish sample, and .56 to .90 in the British sample, with one exception. The Cronbach's alphas and CR values are greater than .70, with a few exceptions that are still above .60 (see Table 4). The average variances extracted are slightly below their expected values (.34-.73), but the square roots range from .58 to .85 , higher than any of their respective pairwise correlations, indicating discriminant validity.

[Insert Table 4 about here]

We then tested for measurement and construct invariance to determine whether the response strategies remain invariant across countries. Measurement invariance pertains to the psychometric properties of the measurement scales and includes configural invariance, metric invariance, and scalar invariance. Scalar invariance is a prerequisite for interpreting construct differences (Steenkamp and Baumgartner, 1998). However, full scalar invariance is not necessary, provided at least one item per response strategy is invariant (i.e., partial invariance) (Byrne, 2001). To 
evaluate measurement and construct invariance, we used multigroup CFA models and considered group comparisons across the five countries. Full scalar invariance is not achieved, but after releasing four factor loadings and nine intercept constraints, we establish partial scalar invariance with satisfactory fit indices: The normed chi-square value is 1.53 , RMSEA is .020 [90\% CI: .018, .022 ], SRMR is .049, NNFI is .94, and CFI is .95. The comparative fit indices between an unconstrained model and the partial invariant model are not significantly different $\left(\Delta \chi^{2}=44.5\right.$, $p=.11, \Delta \mathrm{CFI}=.001)$, in support of partial scalar invariance. These results enable us to conduct mean comparisons across countries to test the hypotheses.

\subsection{Impact of cultural differences on response strategy preference}

To test the effect of country on response strategies, we conducted a MANCOVA. We ran post-hoc group comparisons and $F$-tests to test the hypotheses and interpret the effects of country differences on response strategies, as well as the impact of the exchange variables. For our analyses, we used the average scores for each response strategy as dependent variables and the scenario manipulations and country as the fixed factors, with gender, age, problem severity, and social desirability as covariates. Prior to the analysis, we examined the MANCOVA assumptions and found no violations.

The omnibus MANCOVA tests indicate significant differences for the exchange variables and countries. Specifically, we find significant Wilks' lambdas for country $(\Lambda=.77, F=12.96, p$ $<.001)$ and the four exchange variables: economic satisfaction $(\Lambda=.96, F=7.93, p<.001)$, social satisfaction $(\Lambda=.93, F=13.76, p<.001)$, alliance-specific investments $(\Lambda=.99, F=2.65$, $p<.01)$, and alternative availability $(\Lambda=.92, F=16.80, p<.001)$. Of the four hypothesized twoway interactions between country and exchange variables, three are significant: with economic satisfaction $(\Lambda=.96, F=2.20, p<.001)$, social satisfaction $(\Lambda=.96, F=1.81, p<.01)$, and 
alternative availability $(\Lambda=.96, F=2.06, p<.01)$. The interaction between country and alliancespecific investment is not significant. Furthermore, three of the four control variables are significant: age $(\Lambda=.99, F=2.13, p<.05)$, problem severity $(\Lambda=.98, F=3.17, p<.01)$, and social desirability $(\Lambda=.97, F=5.69, p<.05)$. Gender is not significant $(\Lambda=.99, F=.70, p=$ .67). The $F$-values of the corrected model, which reflect variations in the response strategies attributable to country, exchange variables, and covariates, show significant results for all seven response strategies (see Table 5).

[Insert Table 5 about here]

To test the hypotheses, we conducted post-hoc $F$-tests. With regard to the direct effect of country, the univariate $F$-tests show significant differences for all seven strategies (see Table 5): exit $(F=22.53, p<.001)$, opportunism $(F=20.27, p<.001)$, aggressive voice $(F=15.79, p<$ $.001)$, creative voice $(F=11.96, p<.01)$, considerate voice $(F=8.74, p<.001)$, patience $(F=$ $11.09, p<.001)$, and neglect $(F=9.04, p<.001)$.

Hypothesis 1a proposes that in individualist countries, active response strategies are preferred relatively more and passive strategies relatively less than in collectivistic countries. The results of the pairwise comparisons in Table 5 suggest that the hypothesis is fully supported for creative and considerate voices, patience, and neglect. Overall, respondents in the United Kingdom, the Netherlands, and Switzerland - the more individualist countries—are more likely to use creative and considerate voices and less likely to use patience and neglect than respondents in Japan and Turkey, the more collectivist countries. Hypothesis 1a is also partially supported for opportunism (except for Japan) and aggressive voice (except for Switzerland), but it is not supported for exit. Overall then, we find support for Hypothesis 1a.

Hypothesis 2a proposes that in masculine countries, destructive response strategies are 
preferred relatively more and constructive strategies relatively less than in feminine countries. The results of the pairwise comparisons suggest support for the hypothesis for exit and creative and considerate voice in the case of Japan, the most masculine country in our sample, and for considerate voice and neglect in the case of the Netherlands, the most feminine country. For the United Kingdom, the second most masculine country in our sample, we find some support for the hypothesis in relation to exit, opportunism, aggressive voice, patience, and neglect. The results are also consistent with our expectations for Switzerland, which scores in the middle in terms of masculinity. However, the results for Turkey conflict with our expectations. Overall, Hypothesis $2 \mathrm{a}$ receives support.

Hypothesis 3a proposes that in large power distance countries, destructive response strategies are preferred relatively more and constructive strategies relatively less than in small power distance countries. The results of the pairwise comparisons confirm the hypothesis for opportunism, considerate voice, and neglect in the case of Turkey, a country with a large power distance. The hypothesis is also supported for creative and considerate voice in the case of the Netherlands and the United Kingdom, the two countries with the smallest power distance in our sample. For creative and considerate voices, the results for Switzerland are contrary to our expectations, in that respondents in this country scored relatively high. Overall, we uncover partial support for Hypothesis 3a.

Hypothesis 4a proposes that in countries with high uncertainty avoidance, active response strategies are preferred relatively less and passive strategies relatively more than in countries with low uncertainty avoidance. The results of the pairwise comparisons suggest that the hypothesis is fully supported for aggressive, creative, and considerate voices, patience, and neglect. Overall, respondents in the Netherlands and the United Kingdom, the countries with the smallest uncertainty avoidance, are more likely to use aggressive, creative, and considerate voices and less 
likely to use patience and neglect than are respondents in Japan, Turkey, and Switzerland, the countries with the largest uncertainty avoidance. Hypothesis $4 \mathrm{a}$ is also partially supported for opportunism (except for Japan and Turkey). Overall, we find support for Hypothesis 4a.

Consistent with our expectations and across countries, the exchange variables influence response strategy preference. Economic satisfaction has a direct negative effect on exit ( $F=$ $36.82, p<.001)$ and a positive effect on patience $(F=10.53, p<.001)$. Social satisfaction has direct negative effects on exit $(F=67.20, p<.001)$, opportunism $(F=5.71, p<.05)$, and aggressive voice $(F=8.07, p<.01)$ and positive effects on considerate voice $(F=10.01, p<.01)$ and patience $(F=11.93, p<.001)$. Alliance-specific investments have direct negative effects on exit $(F=5.84, p<.05)$ and aggressive voice $(F=3.83, p<.05)$ and a positive effect on considerate voice $(F=11.78, p<.001)$. The lack of attractive alternatives, across countries, has a direct negative effect on exit $(F=92.31, p<.001)$ and neglect $(F=8.77, p<.01)$ and a positive effect on creative voice $(F=32.11, p<.001)$, considerate voice $(F=60.77, p<.001)$, and patience $(F=8.77, p<.01)$.

The interaction effects between the country and economic satisfaction are statistically significant for considerate voice $(F=4.03, p<.01)$ and patience $(F=3.88, p<.01)$ but not for the other response strategies. We provide the interaction plot for considerate voice in Figure 1a and that for patience on Figure 1b. For these two response strategies, the results provide support for Hypothesis 1b, except for Switzerland. In the Netherlands and the United Kingdom, two individualistic countries, the positive effects of economic satisfaction on considerate voice and its negative effects on patience are stronger than they are for Turkey and Japan, the two most collectivist countries in our sample. The results also support Hypothesis $4 \mathrm{~b}$; for Japan and Turkey, two countries with high uncertainty avoidance, the positive effects of economic 
satisfaction on considerate voice and its negative effects satisfaction on patience are stronger than for the low uncertainty avoidance countries, the Netherlands and the United Kingdom.

The interaction effects between country and social satisfaction are statistically significant for exit $(F=3.62, p<.01)$ and opportunism $(F=2.47, p<.01)$ and not significant for the other response strategies. The interaction plot for exit appears in Figure 1c; that for opportunism is in Figure 1d. The results provide partial support for Hypothesis $2 b$, because the more feminine Netherlands indicates a stronger negative effect of social satisfaction on exit than Turkey, with its medium level of masculinity, and the United Kingdom, with its very masculine culture. However, the significant effect of social satisfaction in Japan, a masculine culture, on exit contrasts with our expectations. In addition, for opportunism, social satisfaction has the strongest effect in the Netherlands compared with the more masculine countries, in line with our expectations. However, contrary to our expectations, the effects of social satisfaction in Turkey and Switzerland are weaker than they are in Japan and the United Kingdom. The results also provide partial support for Hypothesis 3b: For Japan, Turkey, and Switzerland, the three countries with the largest power distances in our sample, the negative effect of social satisfaction on exit is stronger than it is for the United Kingdom, the country with smallest power distance, but it is not stronger than that for the Netherlands.

The interaction effects between country and alternative availability are statistically significant for exit $(F=4.71, p<.001)$, considerate voice $(F=2.46, p<.05)$, patience $(F=2.91$, $p<.05)$, and neglect $(F=2.40, p<.05)$ but not for the other response strategies. We provide the interaction plot for exit in Figure 1e and that for considerate voice in Figure 1f, with the plots for patience in Figure 1g and for neglect in Figure 1h. For these four response strategies, the results support Hypothesis 1c. In the Netherlands and Switzerland, two individualistic countries, the negative effect of alternative availability on considerate voice and its positive effect on exit are 
stronger than those for Turkey, the most collectivist country in our sample. In addition, the positive effects of alternative availability on patience and neglect are stronger for the United Kingdom, the most individualist country in our sample, than for Turkey. The results also provide support for Hypothesis 4c by showing that for Japan, the country with the highest uncertainty avoidance, the negative effect of alternative availability on considerate voice and its positive effects on exit, patience, and neglect are stronger than the United Kingdom, the country with lowest uncertainty avoidance.

[Insert Figure 1 about here]

Among the control variables, age, problem severity, and social desirability have significant effects on response strategy preference. Age has significant effects on creative voice $(F=4.07, p$ $<.05)$ and considerate voice $(F=5.67, p<.05)$; the post-hoc tests reveal that older respondents are more likely to use creative and considerate voices than are younger ones. Problem severity influences exit $(F=3.87, p<.05)$ and patience $(F=10.80, p<.001)$; the more severe the perception of the situation, the more likely respondents are to exit and the less likely they are to be patient. Social desirability has a significant effect on preferences for several response strategies: opportunism $(F=24.87, p<.001)$, creative voice $(F=8.06, p<.01)$, considerate voice $(F=16.33, p<.001)$, and neglect $(F=3.85, p<.05)$. Respondents with high scores on the social desirability scale are less likely to act opportunistically and neglectfully and more likely to choose creative and considerate voices than are respondents with low social desirability scores. The effect of gender is not significant though.

\subsection{External validity test}

To assess the external validity of our measurement scales and scenario manipulations, we compared the results of the Dutch managers and business students in two steps. First, we used 
multigroup CFA to test measurement invariance across the two groups. The results exhibit full metric and partial scalar invariance (four intercepts released) with satisfactory fit indices: The normed chi-square value is 1.54 , RMSEA is .034 [ $90 \% \mathrm{CI}$ : .028, .039], SRMR is .077, NNFI is .94 , and CFI is .95 . The comparative fit indices between the unconstrained model and the partial scalar equivalent model are not statistically significant $\left(\Delta \chi^{2}=17.0, p=.11, \Delta \mathrm{CFI}=.002\right)$, in support of partial scalar measurement invariance between the future and actual manager samples.

Second, we ran a MANCOVA with the seven response strategies as dependent variables; the four exchange variables as fixed factors; a fixed factor sample to denote future and actual managers; and age, gender, problem severity, and social desirability as covariates. We also included two-way interactions in the model. If the sample and sample-exchange variable interactions are not significant, we can confirm the external validity of the business student sample, because no difference in response strategy preferences would exist between the future and actual manager samples. Consistent with our expectations, the omnibus MANCOVA tests indicate significant differences for the four exchange variables, but not for the sample factor. Specifically, we find significant Wilks' lambdas for economic satisfaction $(\Lambda=.95, F=3.27, p<$ $.01)$, social satisfaction $(\Lambda=.89, F=7.71, p<.001)$, alliance-specific investments $(\Lambda=.97, F=$ $2.29, p<.05)$, and alternative availability $(\Lambda=.96, F=2.80, p<.01)$ but not for the sample factor $(\Lambda=.99, F=.70, p=.68)$. The four interactions between the sample factor and the exchange variables are not significant at 5\%; the only significant two-way interaction is between the sample factor and problem severity $(\Lambda=.97, F=2.29, p<.05)$ for two response strategies: patience $(F=5.84, p<.05)$ and neglect $(F=11.35, p<.001)$. That is, actual managers are more patient and neglectful than future managers when problem severity increases. Overall, these results provide support for the external validity of our measures and experimental design. 


\section{Discussion}

This study investigates cross-country differences in preferences for using seven response strategies in international strategic alliances. A scenario-based experiment among 1,379 students acting as alliance managers from five countries_-Japan, the Netherlands, Switzerland, Turkey, and the United Kingdom—demonstrates that country directly influences the preference for response strategies and moderates the effects of economic and social satisfaction and the availability of alternatives.

\subsection{Interpretation of main results}

Respondents in Japan, a country characterized by high scores on masculinity and uncertainty avoidance and medium scores on individualism and power distance, are more likely to use exit and patience; less likely to use opportunism, creative voice, and considerate voice; and indifferent toward aggressive voice and neglect compared with respondents from other countries. This summary indicates that for Japanese respondents, preferences for destructive response strategies and the rejection of constructive response strategies likely reflects a high level of masculinity and, to some extent, a medium level of power distance. Although the results for the passive responses cannot be explained by the direct effects of the cultural dimensions, the country interactions with economic satisfaction and alternative availability suggest that sensitivity to these exchange variables, due to high uncertainty avoidance, affects response strategy preferences. Similarly, high masculinity makes Japanese respondents less sensitive to social satisfaction, which explains their low preference for opportunism.

Respondents in the Netherlands, a country characterized by high individualism, medium to low scores on uncertainty avoidance, and low scores on masculinity and power distance, are more likely to use considerate and creative voices and less likely to use patience and neglect. They are 
indifferent toward exit, opportunism, and aggressive voice. The preference for activeconstructive responses and rejection of passive-destructive responses may be attributed to the effect of high individualism and low power distance and masculinity. The low preference for passive-destructive responses also implies that the effect of individualism is stronger than the effect of power distance and masculinity on their response strategies.

Compared with respondents from the other countries, those in Switzerland, a country characterized by high power distance, medium to high scores on individualism and uncertainty avoidance, and medium scores on masculinity, are less likely to prefer exit, aggressive voice, and patience but are indifferent toward opportunism, creative and considerate voices, and neglect. The medium to high levels of individualism and uncertainty avoidance explain the low preference for passive response strategies. However, the high level of power distance does not seem to influence response strategy preference. The Swiss respondents revealed the lowest scores on aggressive voice, which cannot be explained by the moderating effect of national culture.

We find that respondents in Turkey, a country characterized by high scores on uncertainty avoidance and power distance, medium scores on masculinity, and low scores on individualism, are more likely to use patience, neglect, and opportunism; less likely to use exit and creative and considerate voices; and indifferent toward aggressive voice, compared with respondents from the other countries. The preference for passive response and low preference for active strategies stems from the low level of individualism. Although the high level of uncertainty avoidance seems not to influence response strategy preference, the preference for destructive response strategies is affected by a high score on power distance and medium score on masculinity. The exit results cannot be explained by the direct of effect of cultural dimensions, but the relatively low preference for exit, compared with that in other countries, may be explained by Turkish respondents' lower sensitivity to social satisfaction and alternative availability. 
Finally, respondents in the United Kingdom, a country characterized by high scores on individualism and masculinity and low scores on power distance and uncertainty avoidance, are more likely to prefer exit and aggressive, creative, and considerate voices; less likely to use patience and neglect; and indifferent toward opportunism. High individualism leads to a preference for active but not for passive responses, whereas high masculinity results in a preference for destructive responses.

Taken together, these results indicate that the four cultural dimensions, both directly and interactively with exchange variables, affect the degree of activeness-passiveness and constructiveness-destructiveness of response strategy preference. Specifically, individualismcollectivism and uncertainty avoidance influence the degree of activeness-passiveness and moderate the effect of economic satisfaction and alternative availability. In addition, masculinityfemininity and power distance influence the degree of constructiveness-destructiveness and moderate the effect of social satisfaction. The interaction between country and alliance-specific investments is not significant. One explanation for this finding is that managers across cultures perceive such investments as equally critical for relationship development, such that the criticality of these investments overrides cultural differences.

\subsection{Theoretical and managerial implications}

Our study was conducted in an experimental setting with business students, however, because the cultural effects we tested pertain to basic characteristics of human nature, we believe that our results have some theoretical and managerial implications that are broader than the narrow context in which they were tested.

Drawing on social exchange theory (Blau, 1964) and interdependence theory (Thibaut and Kelley, 1959), response strategy research has proposed an investment model (e.g., Geyskens and 
Steenkamp, 2000; Ping, 1993; Rusbult and Zembrodt, 1983) in which satisfaction with exchange outcomes, specific investments, and the availability of alternatives drive preferences for response strategies. In an international context, this model also should incorporate cross-cultural differences, because people from different countries prefer different responses when confronted with similar adverse situations. The results of our study contribute to response strategy literature by demonstrating that preferences for response strategies vary across cultures.

Extant ISA studies demonstrate that cultural differences affect relationship development, because they tend to exacerbate adverse situations (e.g., Barkema and Vermeulen, 1997; Brouthers and Bamossy, 2006). We improve understanding of this issue by shifting attention from the overall effect of cultural differences to the underlying direct and moderating mechanisms through which national cultures influence managers' decision making (Boyacigiller and Adler, 1991). Just as people from different countries generally prefer different response strategies, their reactions depend on different types of adversity, which corroborates the findings of Thomas and Au (2002) and Thomas and Pekerti (2003). When faced with the same adverse situation, our future managers respondents from different countries likely prefer different response strategies, depending on the strategies they believe will be most adequate in their cultural environment. This point is critical for the management of ISAs, because managers with a better understanding of the behavioral intentions of their foreign partners, as well as their own preferences, can better overcome adverse situations.

Prior studies (e.g., Brouthers and Bamossy, 2006; Meschi, 1997) also suggest that learning about cultural differences can reduce the negative effect of adverse situations. By disentangling the direct and moderating mechanisms through which national culture influences reactions to adverse situations, our study provide managers with a better understanding of how to deal with adverse situations in ISAs more effectively and thus should help them reduce the likelihood of 
failure. An alliance manager from an individualistic country who understands that social satisfaction may be more important than economic satisfaction for his or her counterpart from a collectivist country will be better equipped to deal with the adverse situation and preserve the alliance. Alliance managers who are able to predict which response strategies their foreign counterparts prefer should be able to develop a collaborative relationship more easily and avoid detrimental conflicts.

\subsection{Limitations and further research directions}

Although we believe our results offer important contributions to the international strategic alliance literature and practice, our study is limited in several respects. First, we collected data in only five countries; further studies should collect data from a wider variety of countries to further disentangle the direct and moderating effects of national culture more clearly. Second, we focused on the effect of national culture on response strategy preference, without measuring cultural values directly; instead we used Hofstede's scores to classify countries along the four cultural dimensions. As these scores are not without critics and pertain to country level only, measuring cultural values at the individual level would be necessary to understand both inter- and intracountry differences. Third, by not measuring cultural values, we have been limited to testing country differences rather than cultural differences. Therefore, our results should be interpreted with caution, because other contextual variables, such as country wealth and level of development, may have affected the results. Fourth, we conducted a scenario-based experiment and measured behavioral intentions, which is appropriate for determining the direct and indirect effects of national culture on response strategy preference. However, behavioral intentions do not always translate into behavior. Fifth, the use of an experimental design with business students as respondents increases the internal validity of the results but also may raise questions about 
external validity. Although a comparison of the results of the Dutch student sample with those of a survey of Dutch alliance managers indicates satisfactory level of convergence, our results about the direct and moderating effects of culture might only be generalizable to a population of future managers rather than actual managers. Therefore, further studies should conduct survey research to validate the results with managers across countries. Studying managers' work experience also might be relevant, because our results indicate that age, which we use as a proxy for experience, has a significant effect on two response strategies (i.e., creative and considerate voices).

\section{Conclusion}

In the context of response strategies, our results indicate that country differences directly affect preferences for the activeness-passiveness and constructiveness-destructiveness of responses. In addition, country differences appear to influence the perception of the adversity of the situation. Although these results come from the particular context of international strategic alliances, they provide valuable insights into the effect of national culture on response behavior in general. Response strategies share similarities with coping strategies (e.g., Radford et al., 1993) and conflict resolution styles (e.g., Morris et al., 1998), which also entail active-passive and constructive-destructive behaviors. Thus, our findings about the differential effects of country may apply in these contexts too, though this assertion requires empirical confirmation. 


\section{References}

Aharoni, Y., Brock, D.M., 2010. International business research: Looking back and looking forward. Journal of International Management 16, 5-15.

Ariño, A., de la Torre, J., Ring, P.S., 2001. Relational quality: Managing trust in corporate alliances. California Management Review 44, 109-131.

Barkema, H.G., Vermeulen, F., 1997. What differences in the cultural backgrounds of partners are detrimental for international joint ventures? Journal of International Business Studies 28, 845-864.

Bateman, T.S., Zeithaml, C.P., 1989. The psychological context of strategic decisions: A model and convergent experimental findings. Strategic Management Journal 10, 59-74.

Bello, D., Leung, K., Radebaugh, L., Tung, R., Van Witteloostuijn, A. 2009. From the Editors: Student samples in international business research. Journal of International Business Studies $40,361-364$.

Blau, P.M. 1964. Exchange and Power in Social Life. Wiley, New York.

Boyacigiller, N.A., Adler, N.J. 1991. The parochial dinosaur: Organizational science in a global context. Academy of Management Review 16, 262-290.

Brouthers, K.D., Bamossy G.J., 2006. Post-formation processes in Eastern and Western European joint ventures. Journal of Management Studies 43, 203-229.

Buchanan, L., 1992. Vertical trade relationships: the role of dependence and symmetry in attaining organizational goals. Journal of Marketing Research 29, 65-75.

Byrne, B.M., 2001. Structural Equation Modeling with AMOS: Basic Concepts, Applications, and Programming. Lawrence Erlbaum Associates, Mahway, NJ.

Croson, R., Anand, J., Agarwal, R. 2007. Using experiments in corporate strategy research. European Management Review 4, 173-181.

Das, T.K., 2006. Strategic alliance temporalities and partner opportunism. British Journal of Management 17, 1-21.

Doney, P.M., Cannon, J.P., Mullen, M.R., 1998. Understanding the influence of national culture of the development of trust. Academy of Management Review 23, 601-620.

Farrell, D., 1983. Exit, voice, loyalty, and neglet as responses to job dissatisfaction: A multidimensional-scaling study. Academy of Management Journal 26, 596-607.

Geyskens, I., Steenkamp, J.-B.E.M., 2000. Economic and social satisfaction: Measurement and 
relevance to marketing channel relationships. Journal of Retailing 76, 11-32.

Hagedoorn, M., Yperen, N.W., Van de Vliert, E., Buunk, B.P., 1999. Employees' reactions to problematic events: A circumplex structure of five categories of respones, and the role of job satisfaction. Journal of Organizational Behavior 20, 309-321.

Hibbard, J.D., Kumar, N., Stern, L.W., 2001. Examining the impact of destructive acts in marketing channel relationships. Journal of Marketing Research 38, 45-61.

Hirschman, A.O., 1970. Exit, Voice and Loyalty: Responses to Decline in Firms, Organizations and States. Harvard University Press, Cambridge, MA.

Hofstede, G., 2001. Culture's Consequences, 2nd ed. Sage, Thousand Oaks, CA.

Hofstede, G., Usunier, J.-C., 2003. Hofstede's dimensions of culture and their influence on international business negotiations, in Ghauri, P.N., Usunier, J.-C. (Eds.), International Business Negotiation, 2nd ed. Elsevier, Oxford, pp. 137-153.

Hu, L.T., Bentler, P.M., 1999. Cutoff criteria for fit indexes in covariance structure analysis: conventional criteria versus new alternatives. Structural Equation Modeling 6, 1-55.

Huberty, C. J., Morris, J. D., 1989. Multivariate analysis versus multiple univariate analyses. Psychological Bulletin 105, 302-308.

Jiang, X., Li, Y., Gao, S., 2008. The stability of strategic alliances: Characteristics, factors, and stages. Journal of International Management 14, 173-189.

Joardar, A., Kostova, T., Ravlin, E.C., 2007. An experimental study of the acceptance of a foreign newcomer into a workgroup. Journal of International Management 13, 513-537.

Johnson, J. L., Cullen, J. B., Sakano, T., Takenouchi, H. 1996. Setting the stage for trust and strategic integration in Japanese-U.S. cooperative alliances. Journal of International Business Studies, 27, 981-1004.

Kirkman, B.L., Lowe, K.B., Gibson, C.B. 2006. A quarter century of "Culture's Consequences": A review of empirical research incorporating Hofstede's cultural values framework. Journal of International Business Studies 37, 285-320.

Leck, J. D., Saunders, D. M. 1992. Hirschman's loyalty: Attitude or behavior? Employee Responsibilities and Rights Journal, 5, 219-230.

Lee, J., Jablin, F.M., 1992. A cross-cultural investigation of exit, voice, loyalty and neglect as responses to dissatisfying job conditions. Journal of Business Communication 29, 203-228. McDonald, R.P., Ho, M.-H.R., 2002. Principle and practice in reporting structural equation 
analyses. Psychology Methods 7, 64-82.

Meschi, P.-X., 1997. Longevity and cultural differences of international joint ventures: toward time-based cultural management. Human Relations 50, 211-228.

Morris, M.W. et al., 1998. Conflict management style: Accounting for cross-national differences. Journal of International Business Studies 29, 729-748.

Nakana, C. 1971. Japanese society. Berkeley: University of California Press.

Nakos, G., Brouthers, K.D., 2008. International alliance commitment and performance of small and medium-size enterprises: The mediating role of process control. Journal of International Management 14, 124-137.

Nunnally, J.C., Bernstein, I.H., 1994. Psychometric Theory, 3rd ed. McGraw-Hill, New York.

Park, S.H., Ungson, G.R., 2001. Interfirm rivalry and managerial complexity: A conceptual framework of alliance failure. Organization Science 12, 37-53.

Perrinjaquet, A., Furrer, O. Usunier, J.-C., Cestre, G., Valette-Florence, P. 2007. A test of the quasi-circumplex structure of human values. Journal of Research in Personality 41, 820-840.

Ping, R.A., 1993. The effects of satisfaction and structural constraints on retailer exiting, voice, loyalty, opportunism, and neglect. Journal of Retailing 69, 320-352.

Pressey, A.D., Qu, X.X., 2007. Buyer-supplier relationship dissolution: The Chinese context. Journal of Business \& Industrial Marketing 69, 320-352.

Radford, M.H.B., Mann, L., Ohta, Y., Nakane, Y., 1993. Differences between Australian and Japanese students in decisional self-esteem, decisional stress, and coping styles. Journal of Cross-Cultural Psychology 24, 284-297.

Ralston, D.A., Egri, C. P., Reynaud, E., Srinivasan, N., Furrer, O., et al. in press. A $21^{\text {st }}$ century assessment of values across the global workforce. Journal of Business Ethics, forthcoming.

Rusbult, C.E., Farrell, D. 1983. A longitudinal test of the investment model: The impact on jobsatisfaction, job commitment, and turnover of variations in rewards, costs, alternatives, and investments. Journal of Applied Psychology 68, 429-438.

Rusbult, C.E., Farrell, D., Rogers, G., Mainous, A.G., 1988. Impact of exchange variables on exit, voice, loyalty, and neglect: An integrative model of responses to declining job satisfaction. Academy of Management Journal 31, 599-627.

Rusbult, C.E., Zembrodt, I.M., 1983. Responses to dissatisfaction in romantic involvements: A multidimensional-scaling analysis. Journal of Experimental Social Psychology 19, 274-293. 
Rusbult, C. E., Zembrodt, I. M., Gunn, L. K. 1982. Exit, voice, loyalty, and neglect: responses to dissatisfaction in romantic involvements. Journal of Personality and Social Psychology, 43, $1230-1242$.

Steenkamp, J.-B.E.M., Baumgartner, H., 1998. Assessing measurement invariance in crossnational consumer research. Journal of Consumer Research 25, 78-90.

Strahan, R., Gerbasi, K.C., 1972. Short, homogeneous versions of Marlow-Crowne social desirability scale. Journal of Clinical Psychology, 28, 191-193.

Taras, V., Rowney, J., Steel, P., 2009. Half a century of measuring culture: Review of approaches, challenges, and limitations based on the analysis of 121 instruments for quantifying culture. Journal of International Management 15, 357-373.

Taras, V., Steel, P., Kirkman, B.L. in press. Improving national cultural indices. A meta-analysis of Hofstede's dimensions. Journal of World Business, forthcoming.

Thibaut, J.W., Kelley, H.H. 1959. The Social Psychology of Groups. Wiley, New York.

Thomas, D.C., Au, K., 2002. The effect of cultural differences on behavioral responses to low job satisfaction. Journal of International Business Studies 33, 309-326.

Thomas, D.C., Au, K., Ravlin, E.C., 2003. Cultural variation and the psychological contract. Journal of Organizational Behavior 25, 451-471.

Thomas, D.C., Pekerti, A.A., 2003. Effect of culture on situational determinants of exchange behavior in organizations: A comparison of New Zealand and Indonesia. Journal of CrossCultural Psychology 34, 269-281.

Tjemkes, B., Furrer, O. 2010. The antecedents of response strategies in strategic alliances. Management Decision 48, 1103-1133.

Triandis, H.C., 1995. Individualism and Collectivism. Westview Press, Boulder, CO.

Wathne, K.H., Heide, J.B., 2000. Opportunism in interfirm relationships: Forms, outcomes, and solutions. Journal of Marketing 64, 36-51.

Withey, M.J., Cooper, W.H., 1989. Predicting exit, voice, loyalty, and neglect. Administrative Science Quaterly 34, 521-539.

Yum, Y.-O., 2004. Culture and self-construal as predictors of responses to accommodative dilemmas in dating relationships. Journal of Social and Personal Relationships 21, 817-835.

Zhou, J., George, J.M., 2001. When job dissatisfaction leads to creativity: Encouraging the expression of voice. Academy of Management Journal 44, 682-697. 
Table 1. Scores of Hofstede's Four Cultural Dimensions by Country

\begin{tabular}{lcccccccc}
\hline Country & \multicolumn{2}{c}{$\begin{array}{c}\text { Individualism- } \\
\text { Collectivism }\end{array}$} & \multicolumn{2}{c}{$\begin{array}{c}\text { Masculinity- } \\
\text { Femininity }\end{array}$} & \multicolumn{2}{c}{$\begin{array}{c}\text { Power } \\
\text { Distance }\end{array}$} & \multicolumn{2}{c}{$\begin{array}{c}\text { Uncertainty } \\
\text { Avoidance }\end{array}$} \\
\hline Japan & 46 & $\mathrm{M}$ & 95 & $\mathrm{H}$ & 54 & $\mathrm{M}$ & 92 & $\mathrm{H}$ \\
The Netherlands & 80 & $\mathrm{H}$ & 14 & $\mathrm{~L}$ & 38 & $\mathrm{~L}$ & 53 & $\mathrm{M}-\mathrm{L}$ \\
$\begin{array}{l}\text { Switzerland (French- } \\
\text { speaking part) }\end{array}$ & 64 & $\mathrm{M}-\mathrm{H}$ & 58 & $\mathrm{M}$ & 70 & $\mathrm{H}$ & 70 & $\mathrm{M}-\mathrm{H}$ \\
$\begin{array}{l}\text { Turkey } \\
\text { United Kingdom }\end{array}$ & 37 & $\mathrm{~L}$ & 45 & $\mathrm{M}$ & 66 & $\mathrm{H}$ & 85 & $\mathrm{H}$ \\
\hline Mean & 89 & $\mathrm{H}$ & 66 & $\mathrm{H}$ & 35 & $\mathrm{~L}$ & 35 & $\mathrm{~L}$ \\
\hline
\end{tabular}

Notes: $\mathrm{H}=$ high, $\mathrm{M}=$ medium, $\mathrm{L}=$ low.

Source: Hofstede, 2001. 


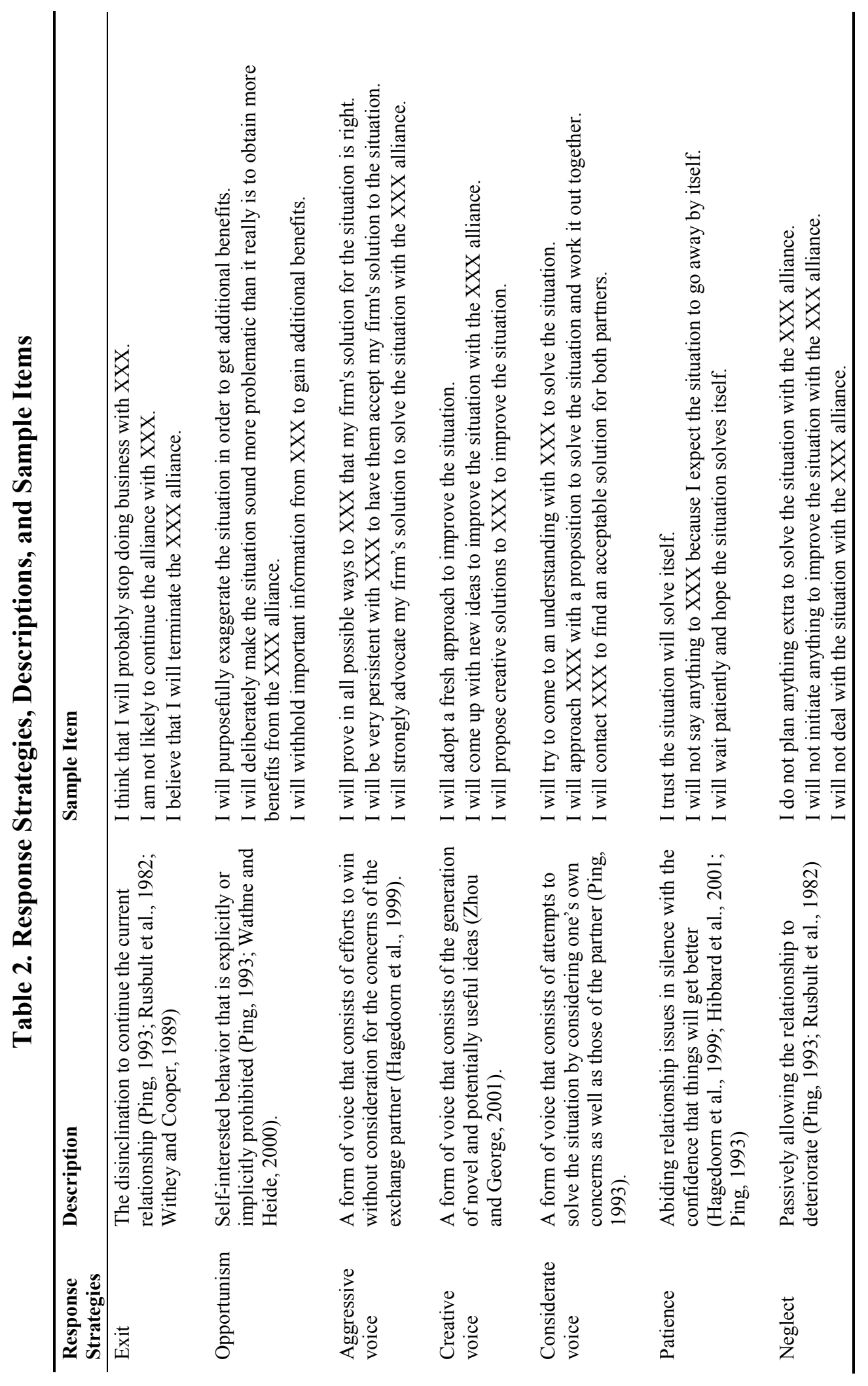




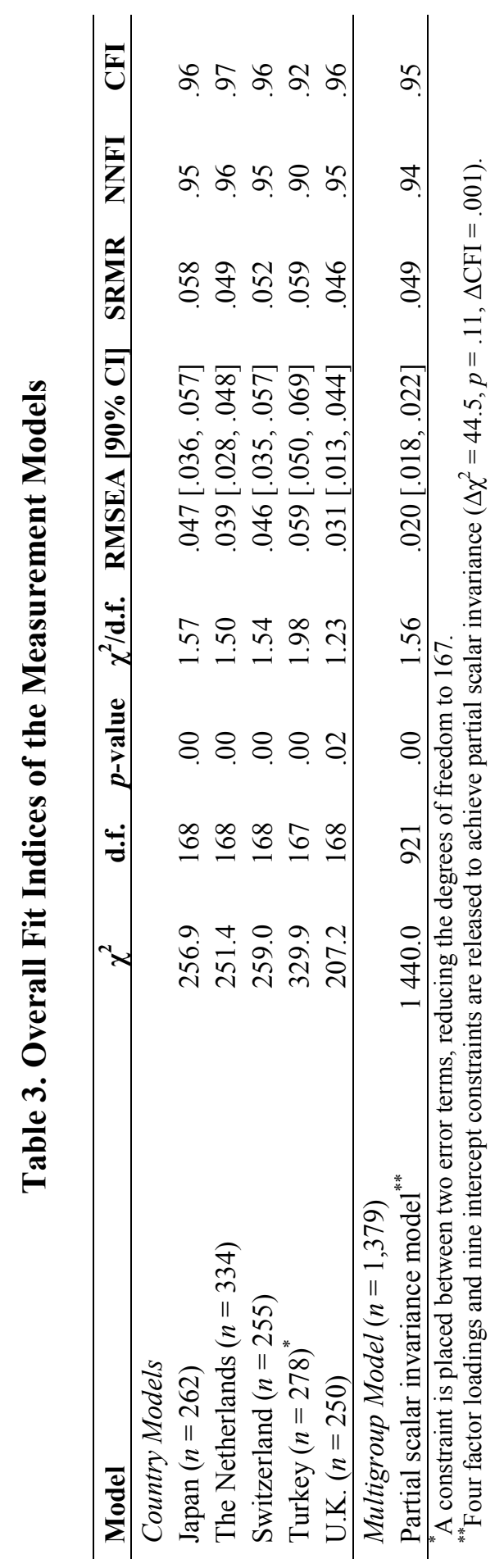


Table 4. Construct Reliability and Partial Correlation Matrices

\begin{tabular}{|c|c|c|c|c|c|c|c|c|c|c|c|}
\hline \multicolumn{12}{|c|}{ A. Japan } \\
\hline Response Strategy & Mean & s.d. & $\alpha$ & CR & AVE & 1 & 2 & 3 & 4 & 5 & 6 \\
\hline 1 Exit & 3.57 & 1.44 & .86 & .86 & .68 & & & & & & \\
\hline 2 Opportunism & 3.01 & 1.23 & .74 & .74 & .49 & $.25^{* * *}$ & & & & & \\
\hline 3 Aggressive voice & 4.48 & 1.00 & .60 & .60 & .34 & $.15^{*}$ & $.31^{* * *}$ & & & & \\
\hline 4 Creative voice & 5.35 & 1.07 & .84 & .85 & .68 & $-.25^{* * *}$ & $-.26^{* * *}$ & $.13^{*}$ & & & \\
\hline 5 Considerate voice & 5.22 & 1.11 & .75 & .75 & .51 & $-.48^{* * *}$ & $-.28^{* * *}$ & .04 & $.60^{* * *}$ & & \\
\hline 6 Patience & 2.31 & 1.10 & .76 & .76 & .51 & .05 & $.38^{* * *}$ & .01 & $-.35^{* * *}$ & $-.22^{* * *}$ & \\
\hline 7 Neglect & 2.25 & 1.10 & .80 & .80 & .58 & $.25^{* * *}$ & $.42^{* * *}$ & -.01 & $-.45^{* * *}$ & $-.43^{* * *}$ & $.69^{* * *}$ \\
\hline \multicolumn{12}{|l|}{$n=262$} \\
\hline \multicolumn{12}{|c|}{ B. The Netherlands } \\
\hline Response Strategy & Mean & s.d. & $\boldsymbol{\alpha}$ & CR & AVE & 1 & 2 & 3 & 4 & 5 & 6 \\
\hline 1 Exit & 3.09 & 1.40 & .89 & .89 & .73 & & & & & & \\
\hline 2 Opportunism & 3.48 & 1.19 & .70 & .71 & .45 & $.25^{* * *}$ & & & & & \\
\hline 3 Aggressive voice & 4.54 & 1.06 & .74 & .74 & .49 & $.20^{* * *}$ & $.48^{* * *}$ & & & & \\
\hline 4 Creative voice & 5.56 & .86 & .81 & .82 & .61 & $-.30^{* * *}$ & -.07 & .06 & & & \\
\hline 5 Considerate voice & 5.54 & .87 & .75 & .75 & .49 & $-.47^{* * *}$ & $-.11^{*}$ & -.01 & $.55^{* * *}$ & & \\
\hline 6 Patience & 1.92 & .82 & .74 & .75 & .50 & -.07 & .04 & $-.12^{*}$ & $-.20^{* * *}$ & $-.10^{\dagger}$ & \\
\hline 7 Neglect & 2.14 & .87 & .71 & .71 & .45 & $.22^{* * *}$ & $.12^{*}$ & -.01 & $-.37^{* * *}$ & $-.32^{* * *}$ & $.46^{* * *}$ \\
\hline \multicolumn{12}{|l|}{$n=334$. } \\
\hline \multicolumn{12}{|c|}{ C. Switzerland } \\
\hline Response Strategy & Mean & s.d. & $\boldsymbol{\alpha}$ & $\mathbf{C R}$ & AVE & 1 & 2 & 3 & 4 & 5 & 6 \\
\hline 1 Exit & 2.95 & 1.44 & .89 & .89 & .73 & & & & & & \\
\hline 2 Opportunism & 3.28 & 1.24 & .72 & .74 & .49 & .06 & & & & & \\
\hline 3 Aggressive voice & 4.11 & 1.09 & .72 & .72 & .47 & .09 & $.41^{* * *}$ & & & & \\
\hline 4 Creative voice & 5.54 & .88 & .78 & .80 & .59 & $-.42^{* * *}$ & -.06 & .08 & & & \\
\hline 5 Considerate voice & 5.37 & .99 & .72 & .72 & .46 & $-.47^{* * *}$ & $-.16^{* *}$ & .01 & $.60^{* * *}$ & & \\
\hline 6 Patience & 1.92 & .92 & .77 & .77 & .53 & .01 & $.21^{* * *}$ & -.02 & $-.27^{* * *}$ & $-.24^{* * *}$ & \\
\hline 7 Neglect & 2.22 & .99 & .77 & .77 & .53 & $.34^{* * *}$ & $.35^{* * *}$ & .08 & $-.47^{* * *}$ & $-.50^{* * *}$ & $.51^{* * *}$ \\
\hline \multirow{2}{*}{\multicolumn{12}{|c|}{$n=255$}} \\
\hline & & & & & & & & & & & \\
\hline Response Strategy & Mean & s.d. & $\boldsymbol{\alpha}$ & CR & AVE & 1 & 2 & 3 & 4 & 5 & 6 \\
\hline 1 Exit & 3.13 & 1.31 & .82 & .83 & .61 & & & & & & \\
\hline 2 Opportunism & 3.85 & 1.22 & .67 & .69 & .43 & $.10^{\dagger}$ & & & & & \\
\hline 3 Aggressive voice & 4.40 & 1.04 & .68 & .68 & .41 & .03 & $.32^{* * *}$ & & & & \\
\hline 4 Creative voice & 5.27 & 1.06 & .78 & .81 & .59 & $-.40^{* * *}$ & .08 & $.26^{* * *}$ & & & \\
\hline 5 Considerate voice & 5.15 & 1.02 & .68 & .68 & .42 & $-.48^{* * *}$ & -.04 & $.15^{*}$ & $.72^{* * *}$ & & \\
\hline 6 Patience & 2.32 & 1.17 & .78 & .78 & .54 & $.23^{* * *}$ & .09 & $-.11^{\dagger}$ & $-.37^{* * *}$ & $-.30^{* * *}$ & \\
\hline 7 Neglect & 2.58 & 1.17 & .71 & .71 & .45 & $.48^{* * *}$ & .11 & -.06 & $-.57^{* * *}$ & $-.55^{* * *}$ & $.59^{* * *}$ \\
\hline \multicolumn{12}{|l|}{$n=278$} \\
\hline \multicolumn{12}{|c|}{ E. United Kingdom } \\
\hline Response Strategy & Mean & s.d. & $\boldsymbol{\alpha}$ & CR & AVE & 1 & 2 & 3 & 4 & 5 & 6 \\
\hline 1 Exit & 3.76 & .80 & .68 & .69 & .43 & & & & & & \\
\hline 2 Opportunism & 3.76 & .68 & .69 & .69 & .43 & .07 & & & & & \\
\hline 3 Aggressive voice & 4.78 & .69 & .77 & .77 & .53 & $.12^{\dagger}$ & -.01 & & & & \\
\hline 4 Creative voice & 5.70 & .65 & .68 & .68 & .41 & .06 & -.02 & $.14^{*}$ & & & \\
\hline 5 Considerate voice & 5.50 & .74 & .64 & .64 & .38 & .03 & .03 & .01 & $.25^{* * *}$ & & \\
\hline 6 Patience & 1.94 & .65 & .77 & .78 & .54 & $.12^{\dagger}$ & -.02 & -.02 & $-.28^{* * *}$ & $-.16^{*}$ & \\
\hline 7 Neglect & 2.20 & .69 & .64 & .68 & .44 & -.02 & .04 & -.01 & $-.21^{* *}$ & -.10 & $.38^{* * *}$ \\
\hline
\end{tabular}

$n=250$.

Notes: s.d. $=$ standard deviation. $\alpha=$ Cronbach's alpha. $\mathrm{CR}=$ composite reliability. AVE $=$ average variance extracted.

${ }^{\dagger} p<.10 ;{ }^{*} p<.05 ;{ }^{* *} p<.01 ;{ }^{* * *} p<.001$. 


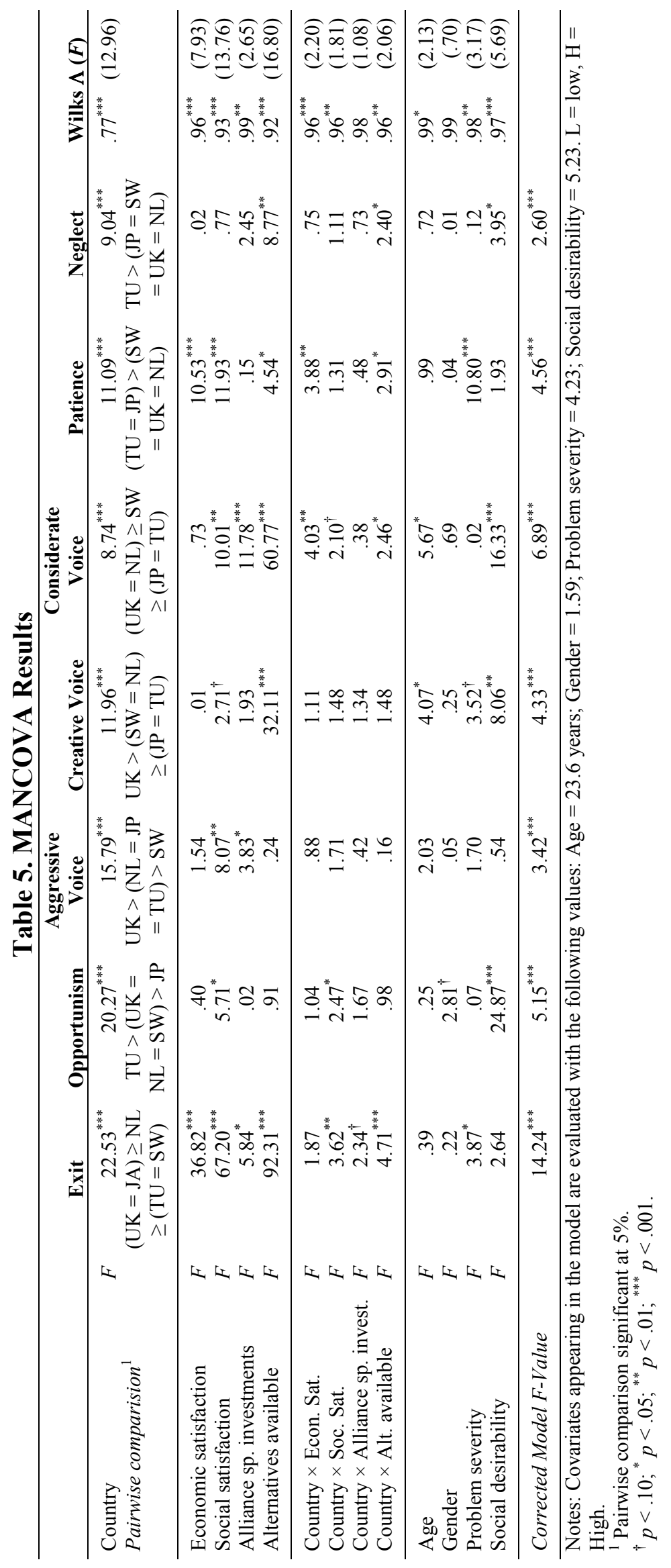


Figure 1. Interaction Effects between Exchange Variables and Countries
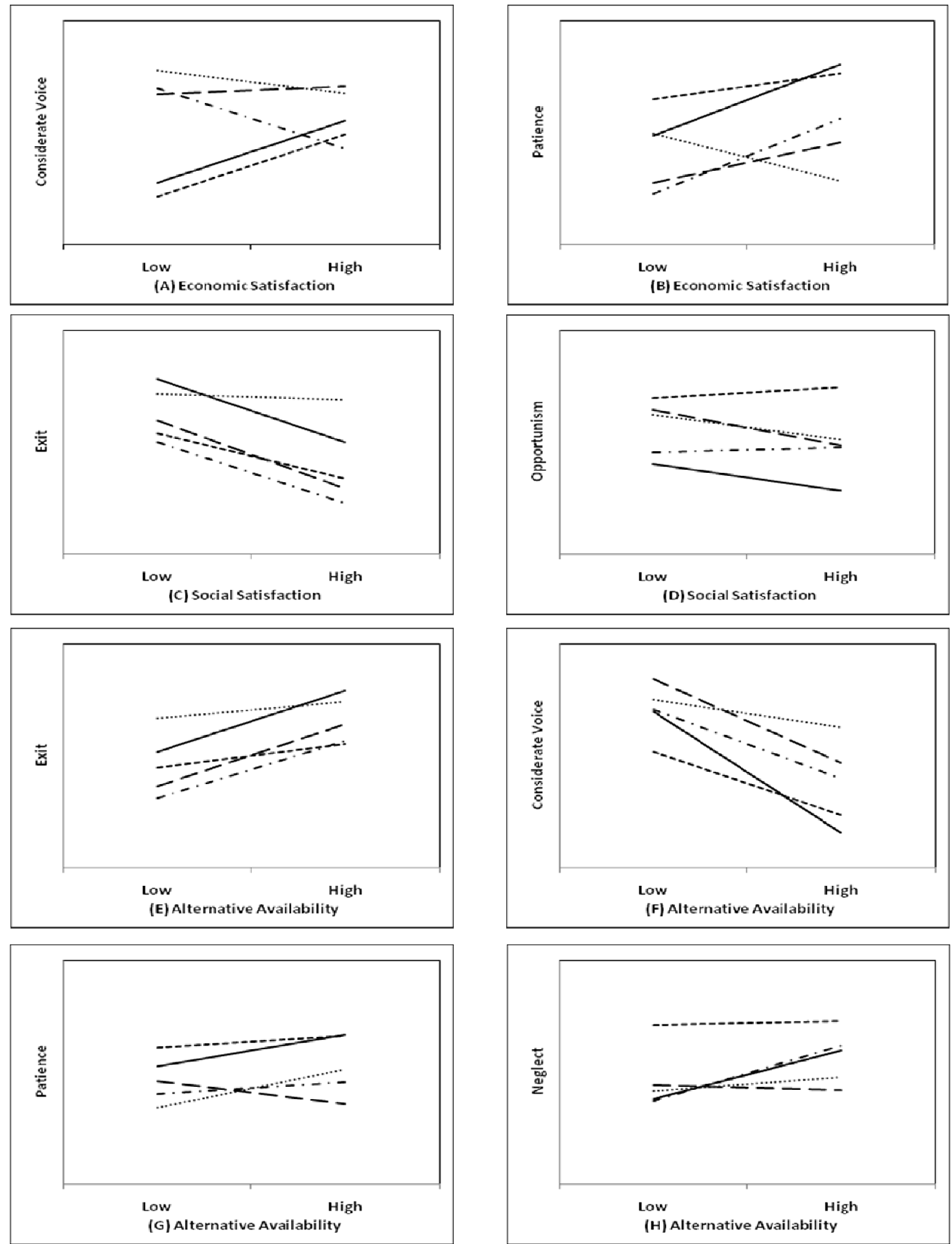

— Japan $\quad$ - The Netherlands

- - Switzerland

-----Turkey

United Kingdom 


\section{APPENDIX: SCENARIO TEXTS}

\section{General Introduction}

Imagine that you are an alliance manager at a firm called BIOPHARM. As an alliance manager you are responsible for all of the strategic alliances BIOPHARM is engaged in. It is your job to assure that the performance of each alliance meets BIOPHARM's expectations. You have the authority and power to make any necessary decisions concerning the future of these alliances. In BIOPHARM's portfolio of alliances, one of the alliances is an international alliance with a foreign partner, STARTECH. This alliance was established five years ago and is equally important for both companies.

\section{$\underline{\text { Manipulations Texts }}$}

\section{Positive}

During the past year, the benefits BIOPHARM derived through the

STARTECH alliance met the firm's expectations. The financial objectives BIOPHARM had set were fully attained. More specifically, the alliance generated more revenues for BIOPHARM than it had initially expected.

\section{Economic satisfaction}

During the past year BIOPHARM's benefits from the STARTECH

alliance did not meet the firm's expectations. The financial

objectives BIOPHARM had set were not fully attained. More specifically, the alliance generated fewer revenues for BIOPHARM than it had initially expected.
Positive

Up until now, STARTECH has been very cooperative and flexible when making necessary adjustments to the alliance. For example, necessary renegotiations to change contractual clauses were usually settled quickly. Consequently, the working relationship with STARTECH went very smoothly as both partners trusted one another completely and BIOPHARM did not need to allocate additional resources to monitor the alliance.

\section{Social satisfaction}

Up until now, STARTECH has not been very cooperative and flexible when making necessary adjustments to the alliance. For example, on one occasion it took extensive renegotiations to change some minor contractual clauses. Consequently, the working relationship with STARTECH became more troublesome since both partners started to distrust one another and BIOPHARM had to allocate additional resources to monitor the alliance.

Positive

\section{Alliance specific investments}

In the past, BIOPHARM made some minor reusable investments to make the alliance with STARTECH work. For example, BIOPHARM has invested into a database, which is useful with or without the STARTECH alliance. In addition, only few additional costs are to be expected if BIOPHARM should terminate the STARTECH alliance. For example, no penalty fee would have to be paid to STARTECH if BIOPHARM prematurely ends the alliance.
Negative In the past, BIOPHARM made substantial specialized investments that would be lost if the STARTECH alliance were to be terminated. For example, BIOPHARM has invested into a tailor-made database, which is only useful, if exploited together with STARTECH. In addition, substantial costs can be expected if BIOPHARM should end the STARTECH alliance. For example, a high penalty fee has to be paid to STARTECH if BIOPHARM prematurely ends the alliance.
Positive

At this moment, BIOPHARM has plentiful alternatives available. For example, launching a new product without STARTECH can be considered as a serious alternative. Moreover, developing new products without STARTECH's help is possible with only a few additional investments. In addition, various other firms can be viewed as potential partners to replace STARTECH and these firms are interested in forming an alliance with BIOPHARM.

\section{Alternatives availability}

Negative For example risky. Moreover, developing new products without STARTECH's help is too costly, as substantial investments would be required. In addition, only a few other firms can be viewed as potential partners to replace STARTECH. In addition, most of these firms are already engaged in other alliances with BIOPHARM's competitors. 